\title{
Noninvasive method for electrocardiogram recording in conscious rats: feasibility for heart rate variability analysis
}

\author{
PEDRO P. PEREIRA-JUNIOR*, MOACIR MAROCOLO*, FABRÍCIO P. RODRIGUES, \\ EMILIANO MEDEI and JOSÉ H.M. NASCIMENTO
}

Universidade Federal do Rio de Janeiro, Instituto de Biofísica Carlos Chagas Filho, CCS, Bloco G, Ilha do Fundão, 21941-902 Rio de Janeiro, RJ, Brasil

Manuscript received on November 18, 2008; accepted for publication on August 31, 2009

\begin{abstract}
Heart rate variability (HRV) analysis consists in a well-established tool for the assessment of cardiac autonomic control, both in humans and in animal models. Conventional methods for HRV analysis in rats rely on conscious state electrocardiogram (ECG) recording based on prior invasive surgical procedures for electrodes/transmitters implants. The aim of the present study was to test a noninvasive and inexpensive method for ECG recording in conscious rats, assessing its feasibility for HRV analysis. A custom-made elastic cotton jacket was developed to fit the rat's mean thoracic circumference, with two pieces of platinum electrodes attached on its inner surface, allowing ECG to be recorded noninvasively in conscious, restrained rats $(n=6)$. Time- and frequency-domain HRV analyses were conducted, under basal and autonomic blockade conditions. High-quality ECG signals were obtained, being feasible for HRV analysis. As expected, mean RR interval was significantly decreased in the presence of atropine $(p<0.05)$ and increased in the presence of propranolol $(\mathrm{p}<0.001)$. Also, reinforcing the reliability of the method, low- and high-frequency HRV spectral powers were significantly decreased in the presence of propranolol $(\mathrm{p}<0.05)$ and atropine $(p<0.001)$, respectively. In summary, the present work describes a novel, inexpensive and noninvasive method for surface ECG recording in conscious rats.
\end{abstract}

Key words: electrocardiography, heart rate variability, methodology, noninvasive, rat.

\section{INTRODUCTION}

The electrocardiogram (ECG) is a remarkably important tool for the study of cardiac electrophysiology, both in the clinical and in the experimental setting. It is known that the rat constitutes an important model for cardiovascular physiology research and, for long, ECG-based studies have been conducted in this animal model.

Heart rate variability (HRV) analysis, a technique that relies on the assessment of fluctuations on the intervals among successive ECG R waves, has been used as a powerful tool for the assessment of cardiac autonomic control (Akselrod et al. 1981, Task Force 1996).

\footnotetext{
*These authors contributed equally to this work Correspondence to: José Hamilton Matheus Nascimento E-mail: jhmn@biof.ufrj.br
}

Decreased HRV is associated with an increased risk for ventricular arrhythmia, and has been shown to constitute an independent prognostic factor for mortality in cardiac patients (Kleiger et al. 1987, Nolan et al. 1998). In rats, power spectral analysis of HRV has been shown to be an effective method of detecting disturbances in cardiac autonomic control in some experimental models of pathologic conditions, such as myocardial infarction and diabetic neuropathy (Krüger et al. 2000, Sanyal et al. 2002).

Approaches based on ECG recording in the anesthetized state lack validity for HRV analysis, since, under anesthesia, heart rate fluctuations related to cardiac autonomic modulation show marked impairment (Uechi et al. 1998, Mäenpää et al. 2007). Besides that, anes- 
thesia may represent an important additional risk for animal mortality in some pathological conditions, such as in myocardial infarction and diabetes models (Tivesten et al. 2000, Flumignan et al. 2006, Cohen-Boulakia et al. 2000). Thus, the development of a new method that does not rely on surgical procedures for electrodes/transmitter implants may be of considerable importance.

Although telemetry represents the gold-standard for ECG recording in rats, the implementation of telemetric systems entails high costs. Additionally, some approaches based on electrodes implants may be limited by progressive decreases in electrodes viability across a couple of days. So, the development and application of a noninvasive method for conscious state ECG recording may represent a consistent alternative approach, allowing long-term HRV studies in the rat model.

Thus, the aim of the present study was to test a noninvasive and inexpensive method for ECG recording in conscious rats, assessing its feasibility for heart rate variability analysis.

\section{MATERIALS AND METHODS}

The study was in accordance with the "Principles of laboratory animal care" (NIH publication No. 85-23, revised 1985), and was approved by the Institution's Animal Care and Use Committee. Experiments were conducted on 6 male Wistar rats (330-370g), kept in cages floored with wood shavings, in a room with constant temperature $\left(23^{\circ} \mathrm{C}\right)$ and $12 \mathrm{~h}$ dark-light cycle. All animals had access to food and water ad libitum.

Prior to ECG recordings, animals were conditioned for 7 consecutive days, 20 minutes each day, inside a plexiglass restrainer. All posterior recordings were conducted on a constant environment, during the morning (0700-0900h).

A day before ECG was firstly recorded, the ventral thoracic region of each animal was carefully shaved. A custom-made elastic cotton jacket was developed to fit the rat's mean thoracic circumference, and two pieces of rectangular platinum electrodes (each one measuring $7.0 \times 3.0 \mathrm{~mm}$ ) were attached on the jacket's inner surface, with each electrode being connected to a cable long enough to reach the acquisition system. Electrodes were spatially disposed in such a way that direct contact to the animal's skin was possible, allowing the ECG to be acquired in a lead close to DII, with prominent $\mathrm{R}$ wave peaks. Details on the jacket can be observed in Figure 1B.

A conductive ECG gel was applied over each electrode, with care being taken to avoid the establishment of a gel bridge between them. After that, the elastic cotton jacket was dressed (Fig. 1A), the animal was placed inside the plexiglass restrainer (Fig. 1C), which had holes on its front end and on its other surfaces, allowing adequate ventilation, and electrodes were connected to a differential A/C amplifier (A-M Systems, USA), with signals being digitized by a 16 bit $\mathrm{A} / \mathrm{D}$ interface converser (Axon 1322-A, USA), and sampled at $10 \mathrm{KHz}$ by the software Axoscope 9.0 (Axon Instruments, USA). Data were stored in a PC for off-line processing. The ECG recording started 10 minutes after the animal was placed inside the plexiglass restrainer, and was conducted for 5 minutes. For each record, the most stable 180 s continuous segment was chosen for HRV analysis. This segment duration was described in previous studies (Mangin et al. 1998, Krüger et al. 2000).

Additional records were conducted on different days (48h interval among them), with animals under vagal and sympathetic blockade conditions. For vagal blockade assessment, animals were treated with the muscarinic antagonist atropine sulfate $\left(2 \mathrm{mg} \mathrm{kg}^{-1}\right.$ i.p., Sigma), while for sympathetic blockade, the beta blocker DL-propranolol hydrochloride was used (4 $\mathrm{mg} \mathrm{kg}^{-1}$ i.p., Sigma). Electrocardiogram records were carried out 10 minutes after drug injection.

All HRV signal processing in the present study was done using Matlab-based algorithms. ECGs were bandpass filtered $(2-300 \mathrm{~Hz})$ and, after $\mathrm{R}$ wave peak detection, 180-s tachograms were generated, containing all heart period fluctuations within this time segment. In the time-domain, the following indexes were obtained: RR (mean RR interval), SDNN (standard deviation of $\mathrm{RR}$ intervals), RMSSD (square root of the mean squared differences of successive RR intervals), and pNN5 [percentage of successive RR interval differences greater than $5 \mathrm{~ms}$, as described by Aubert and colleagues (1999)]. For spectral (frequency-domain) analysis of HRV, tachograms were resampled to equal intervals by spline cubic interpolation method at $10 \mathrm{~Hz}$, and the linear trend was removed. Power spectrum was 


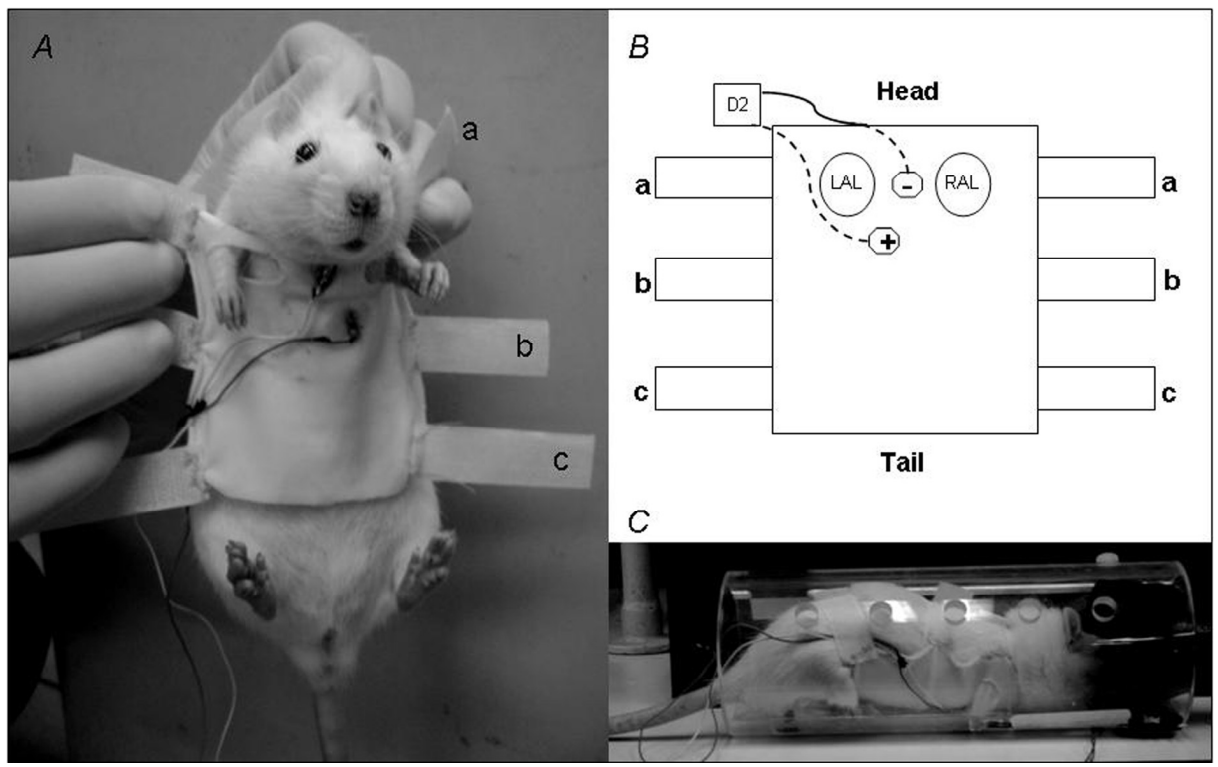

Fig. 1 - ECG acquisition method: A - jacket placement on the rat. B - schematic diagram of the inner face of the jacket, illustrating negative and positive electrodes positions. LAL - left anterior limb; RAL - right anterior limb. C - restrained animal in rest during signal acquisition.

obtained with a fast Fourier transform based method (Welch's periodogram: 256 points, 50\% overlap, and Hamming window). Two frequency bands were determined: low-frequency (LF: $0.2-0.8 \mathrm{~Hz}$ ), and high-frequency (HF: $0.8-2.5 \mathrm{~Hz}$ ). Power (in $\mathrm{ms}^{2}$ ) was estimated as the area under the spectrum within these frequency ranges.

Paired Student's t-tests were conducted in order to compare power spectral indexes (LF and HF powers) before and after autonomic blockades, while mean RR comparisons were carried out by one-way analysis of variance (ANOVA) with Bonferroni post-test. All data are expressed as mean \pm standard error of the mean (SEM). Statistical analysis was performed using GraphPad Prism 4 (GraphPad Software, Inc.). Statistical significance was established at the $\mathrm{p}<0.05$ level.

\section{RESULTS}

Electrocardiography in conscious state animals is a widely used tool for cardiac autonomic control, allowing the extraction of HRV parameters. With the present noninvasive method, we have shown the possibility of acquiring a high-quality ECG signal in non-anesthetized rats, as shown in Figure 2A, presenting an unfiltered ECG segment. As with conventional methods relying on surgical implants of electrodes/transmitters, we showed that the present approach is feasible for HRV analysis in the time- and frequency-domain, as illustrated in Figure $2 \mathrm{~B}$ and Figure $2 \mathrm{C}$, which show, respectively, a representative tachogram and RR power spectrum. Additionally, in Table I we present the individual HRV time- and frequency-indexes from each of the 6 animals used in the present work.

In addition, to assess the HRV responses to autonomic blockades, atropine and propranolol were used. As expected, RR was significantly decreased in the presence of the muscarinic antagonist atropine sulfate $(n=6$; $p<0.05$ ), and increased in the presence of the beta-adrenergic antagonist propranolol $(n=6 ; p<0.001)$, as shown in Figure 3A. Also, reinforcing the reliability of the present method, as expected, low-frequency HRV power was significantly decreased in the presence of propranolol (Fig. 3B; $<<0.05$ ), and high-frequency HRV power was significantly decreased in the presence of atropine sulfate (Fig. 3C; $\mathrm{p}<0.001$ ).

\section{DISCUSSION}

Reduced heart rate variability (HRV) constitutes an independent prognostic factor for cardiac events (Tsuji et al. 1996). To date, evidence exists suggesting also a pos- 

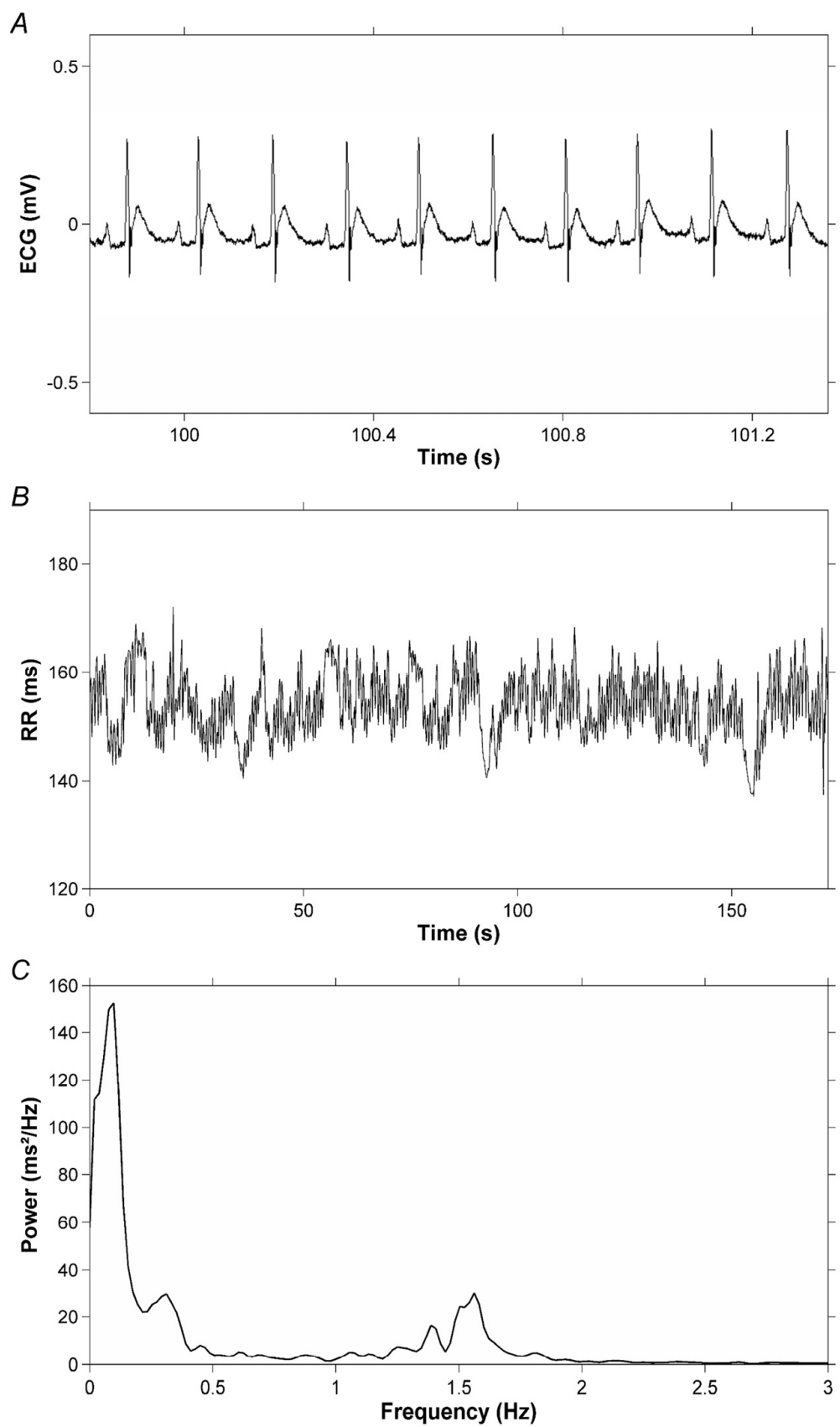

Fig. 2 - HRV graphs extracted from one animal: A - Non-filtered ECG segment tracing. B - Tachogram. C - Power spectrum of RR fluctuations.

sible prognostic value of HRV in rodents (Rowan et al. 2007). The rat has been shown to constitute an important model for the study of HRV, being suitable for investigations involving diseases, toxicological, and environmental approaches (Krüger et al. 2000, Pereira-Junior et al. 2006, Rowan et al. 2007, Chang et al. 2007, Howarth et al. 2008). Besides that, the application of non-linear methods in the study of HRV in rats has been recently described (Beckers et al. 2006).

Conventional methods for conscious state ECG recording in rats rely on surgical procedures for electrodes/ transmitter implants, which are generally conducted one or a few more days before records take place. Our previous experience has shown that inflammatory responses 
TABLE I

Individual HRV parameters.

\begin{tabular}{c|c|c|c|c|c|c|c}
\hline Animal \# & RR $(\mathrm{ms})$ & SDNN $(\mathrm{ms})$ & RMSSD $(\mathrm{ms})$ & pNN5 (\%) & LF Power $\left(\mathrm{ms}^{2}\right)$ & HF Power $\left(\mathrm{ms}^{2}\right)$ & LF/HF \\
\hline 1 & 153.54 & 9.89 & 5.41 & 24.40 & 14.74 & 11.30 & 1.30 \\
\hline 2 & 149.48 & 6.23 & 3.47 & 13.72 & 3.37 & 4.33 & 0.78 \\
\hline 3 & 147.78 & 8.40 & 4.47 & 20.79 & 9.93 & 6.69 & 1.48 \\
\hline 4 & 153.65 & 5.85 & 4.64 & 27.81 & 5.83 & 8.71 & 0.67 \\
\hline 5 & 147.88 & 7.78 & 2.95 & 2.71 & 5.65 & 3.30 & 1.71 \\
\hline 6 & 146.97 & 4.94 & 3.23 & 12.83 & 4.72 & 3.19 & 1.48 \\
\hline Mean & 149.88 & 7.18 & 4.03 & 17.04 & 7.37 & 6.26 & 1.24 \\
\hline S.E.M & 1.21 & 0.75 & 0.39 & 3.74 & 1.72 & 1.34 & 0.17 \\
\hline
\end{tabular}

RR (mean RR interval), SDNN (standard deviation of RR intervals), RMSSD (square root of the mean squared differences of successive RR intervals), pNN5 (percentage of successive RR interval differences greater than $5 \mathrm{~ms}$ ), LF/HF ratio.

to implanted custom-made electrodes generally occur about a week after surgery, leading to progressive worsening in the signal to noise ratio, even resulting in the complete absence of detectable ECG tracings after some days or weeks (data not shown). Long-term ECG recording has already been described with telemetric systems (Howarth et al. 2008). Nevertheless, to our knowledge, no previous report describes long-term ECG recordings using setups based on custom-made implanted electrodes and direct cable connection. Thus, the present method may represent an interesting and inexpensive alternative to telemetry, allowing ECG repeated measures to be taken across a given time period, which may benefit study designs such as the ones used to assess the time course of complications in cardiovascular disease models, drug therapies, or cardiovascular adaptations to exercise training. Besides that, if adequate safety precautions are taken in animal handling, using a noninvasive method may possibly represent a way of reducing the risk of accidental infection, compared to surgical methods, in cases where conscious state ECG recording is necessary in rat models of infectious diseases (eg, Chagas' Disease).

Animal restraining may represent a potential limitation of our method, as no free activity or grooming was possible. Thus, we can not discard the hypothesis that restraining related stress could have some interference on the HRV indexes obtained. Nevertheless, some studies conducted on freely moving Wistar rats presented mean RR values comparable to ours for control animals (Lo Giudice et al. 2002). In the spectrum shown in Fig- ure $2 \mathrm{C}$, it is possible to notice the presence of a lowfrequency spectral peak occurring at about $0.3 \mathrm{~Hz}$, and a high-frequency peak close to $1.5 \mathrm{~Hz}$. This spectral profile being comparable to those presented in previous HRV characterization and validation studies, which were conducted in freely moving rats, and relied on surgical procedures for cable-based data acquisition or telemetric data transmission (Kuwahara et al. 1994, Aubert et al. 1999). Moreover, the normalized LF and HF values obtained in this study are in agreement with previous findings in unrestrained conscious rats with implanted telemeters (Mangin et al. 1998, Ning et al. 2006). Thus, it seems important to remark that previous habituation to the procedure (see Methods) may be a very important requirement for optimizing this noninvasive approach.

Previous works have described blood pressure measurement in conscious rats, allowing the determination of blood pressure variability and baroreflex sensitivity (Ramaekers et al. 2002). We should remark that the present method is only suited for the measurement of $\mathrm{ECG}$, and is not valid if blood pressure recording is also needed.

Another potential limitation of the present method may be due to its potential interference over the rat's respiratory pattern, so we took care to ensure that the custom-made jacket was complacent, in order to minimize this potential issue. In this way, it is important to remark that the intra-group sample dispersion of HF power values are in agree with previous data published by the authors, using implanted electrodes (Pereira-Junior et al. 2006). Besides that, the responses of HRV spectral 

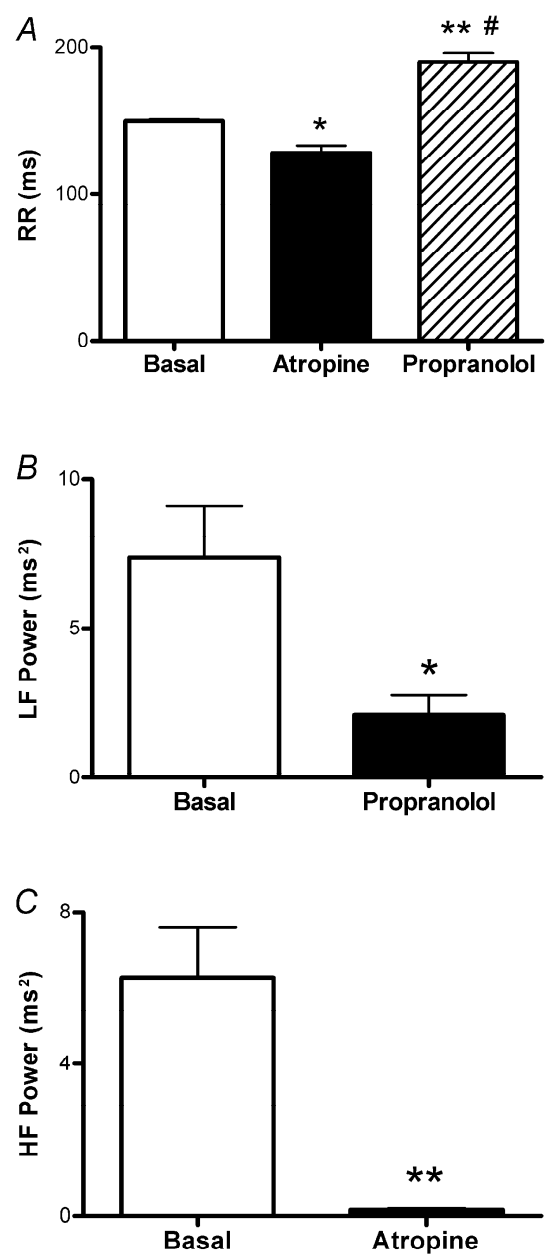

Fig. 3 - Autonomic blockade data: A - Mean RR values under basal conditions and after atropine $\left(2 \mathrm{mg} \mathrm{kg}^{-1}\right)$ or propranolol $\left(4 \mathrm{mg} \mathrm{kg}^{-1}\right)$ blockade. B - Low-frequency spectral power under basal conditions and after propranolol blockade. C - High-frequency spectral power under basal conditions and after atropine blockade. Data expressed as mean \pm SEM. ${ }^{*} \mathrm{p}<0.05$ vs. basal; ${ }^{* *} \mathrm{p}<0.001$ vs. basal; $\# \mathrm{p}<0.001$ vs. atropine. For all conditions, $\mathrm{n}=6$.

indexes to sympathetic and parasympathetic autonomic blockades have shown a similar physiological pattern comparable with previous works in the literature that used telemetric systems (Kuwahara et al. 1994). We should remark that this approach may be specially suited for repeated ECG measures, so that paired comparisons would not be affected by such methodological concerns.

In summary, the present work describes a novel, inexpensive and noninvasive method for surface ECG recording in conscious, restrained rats, which represents a feasible approach for HRV analysis.

\section{ACKNOWLEDGMENTS}

Fundação Carlos Chagas Filho de Amparo à Pesquisa do Estado do Rio de Janeiro (FAPERJ). PPPJ holds a scholarship from Conselho Nacional de Desenvolvimento Científico e Tecnológico (CNPq).

\section{RESUMO}

A análise da variabilidade da freqüência cardíaca (VFC) consiste em uma metodologia bem estabelecida para o estudo do controle autonômico cardíaco, tanto em humanos como em modelos animais. As metodologias convencionais para o estudo da VFC em ratos utilizam-se de procedimentos cirúrgicos para o implante de eletródios ou transmissores, o que possibilita a posterior aquisição do eletrocardiograma (ECG) no estado consciente. O objetivo do presente trabalho foi o de desenvolver e aplicar um método não-invasivo para o registro do ECG em ratos conscientes, verificando sua validade para a análise da VFC. Uma vestimenta de tecido elástico em algodão foi desenvolvida de acordo com as dimensões médias da circunferência torácica dos animais, e dois pequenos eletródios retangulares de platina foram aderidos à superfície interna da vestimenta, permitindo o registro do ECG de forma nãoinvasiva em ratos conscientes $(n=6)$, sob contenção. Foram conduzidas análises de VFC nos domínios do tempo e da freqüência, tanto para a condição basal, como para as condições de bloqueio autonômico. Foram obtidos sinais de ECG de alta qualidade, viáveis para a análise de VFC. Conforme esperado, o intervalo RR médio foi significativamente reduzido na presença de atropina $(\mathrm{p}<0.05)$, e aumentado na presença de propranolol $(\mathrm{p}<0.001)$. Reforçando a validade do método, as potências espectrais de baixa e alta freqüência da VFC sofreram reduções significativas, respectivamente, na presença de propranolol $(\mathrm{p}<0.05)$ e atropina $(\mathrm{p}<0.05)$. Em resumo, o presente trabalho descreve um novo método, de baixo custo e natureza não-invasiva, para a realização do ECG de superfície em ratos conscientes.

Palavras-chave: eletrocardiografia, variabilidade da frequência cardíaca, metodologia, não-invasivo, rato.

\section{REFERENCES}

Akselrod S, Gordon D, Ubel FA, Shannon DC, BerGER AC AND COHEN RJ. 1981. Power spectrum analysis of heart-rate fluctuation - A quantitative probe of beatto-beat cardiovascular control. Science 213: 220-222. 
Aubert AE, Ramaekers D, Beckers F, Breem R, Denef C, VAn de Werf F And Ector H. 1999. The analysis of heart rate variability in unrestrained rats. Validation of method and results. Comput Methods Programs Biomed 60: 197-213.

Beckers F, Verheyden B, RAMAEKERs D, SWyngheDAUW B AND AUBERT AE. 2006. Effects of autonomic blockade on non-linear cardiovascular variability indices in rats. Clin Exp Pharmacol Physiol 33: 431-439.

Chang CC, Hwang JS, Chan CC And Cheng TJ. 2007. Interaction effects of ultrafine carbon black with iron and nickel on heart rate variability in spontaneously hypertensive rats. Environ Health Perspect 115: 1012-1017.

Cohen-Boulakia F, Valensi PE, Boulahdour H, Lestrade R, Dufour-Lamartinie JF, Hort-LeGRAND C AND BEHAR A. 2000. In vivo sequential study of skeletal muscle capillary permeability in diabetic rats: Effect of anthocyanosides. Metabolism 49: 880-885.

Flumignan RL, KANASHiro RM, SARAIVA RM, Portes LA, Antonio EL, Ishigai MM And TuCCi PJ. 2006. Incidence of heart failure in infarcted rats that die spontaneously. Braz J Med Biol Res 39: 1323-1328.

Howarth FC, JaCOBSON M, ShafiUllah M AND Adeghate E. 2008. Long-term effects of type 2 diabetes mellitus on heart rhythm in the Goto-Kakizaki rat. Exp Physiol 93: 362-369.

Kleiger RE, Miller JP, Bigger JT JR AND Moss AJ. 1987. Decreased heart-rate-variability and its association with increased mortality after acute myocardialinfarction. Am J Cardiol 59: 256-262.

Krüger C, Landerer V, ZugCK C, Ehmke H, KÜbler W AND HAASS M. 2000. The bradycardic agent zatebradine enhances baroreflex sensitivity and heart rate variability in rats early after myocardial infarction. Cardiovasc Res 45: 900-912.

Kuwahara M, Yayou K, Ishit K, Hashimoto S, TsubONE H AND Sugano S. 1994. Power spectral analysis of heart rate variability as a new method for assessing autonomic activity in the rat. J Electrocardiol 27: 333-337.

Lo Giudice P, Careddu A, Magni G, Quagliata T, PACIFICI L AND CARMinAti P. 2002. Autonomic neuropathy in streptozotocin diabetic rats: effect of acetyl-Lcarnitine. Diabetes Res Clin Pract 56: 173-180.

MÄenpÄÄ M, PentTilä J, LAitio T, Kaisti K, KuUsela T, HINKKA S AND SCHEININ H. 2007. The effects of surgical levels of sevoflurane and propofol anaesthesia on heart rate variability. Eur J Anaesthesiol 24: 626-633.
Mangin L, Swynghedauw B, Benis A, Thibault N, LEREBOURS G AND CARRÉ F. 1998. Relationships between heart rate and heart rate variability: study in conscious rats. J Cardiovasc Pharmacol 32: 601-607.

Ning G, BAI Y, YAN W AND ZHENG X. 2006. Investigation of beat-to-beat cardiovascular activity of rats by radio telemetry. Clin Hemorheol Microcirc 34: 363-371.

NOLAN J ET AL. 1998. Prospective study of heart rate variability and mortality in chronic heart failure - Results of the United Kingdom heart failure evaluation and assessment of risk trial (UK-Heart). Circulation 98: 1510-1516.

Pereira-Junior PP, Chaves EA, Costa-E-Sousa RH, Masuda MO, De CARVAlho AC and Nascimento JH. 2006. Cardiac autonomic dysfunction in rats chronically treated with anabolic steroid. Eur J Appl Physiol 96: 487-494.

Ramaekers D, Beckers F, Demeulemeester H AND Aubert AE. 2002. Cardiovascular autonomic function in conscious rats: a novel approach to facilitate stationary conditions. Ann Noninvasive Electrocardiol 7: 307-318.

ROWAN III WH, CAMPEN MJ, WiCHERS LB AND WATKINSON WP. 2007. Heart rate variability in rodents: uses and caveats in toxicological studies. Cardiovasc Toxicol 7: $28-51$.

SANYAL SN, ARITA M AND ONO K. 2002. Inhomogeneous derangement of cardiac autonomic nerve control in diabetic rats. Circ J 66: 283-288.

TASK Force of the EUROPEAN SOCIETy OF CARDiolOGY AND THE NORTh AMERICAN SOCIETy OF PACING AND ELECTROPHYSIOLOGY. 1996. Heart rate variability - Standards of measurement, physiological interpretation, and clinical use. Circulation 93: 1043-1065.

Tivesten A, Bollano E, Caidahl K, Kujacic V, Sun XY, Hedner T, Hualmarson A, Bengtsson BA AND ISGAARD J. 2000. The growth hormone secretagogue hexarelin improves cardiac function in rats after experimental myocardial infarction. Endocrinology 141: $60-66$.

Tsuji H, Larson MG, Venditti FJ JR, Manders ES, Evans JC, Feldman CL And Levy D. 1996. Impact of reduced heart rate variability on risk for cardiac events - The Framingham Heart Study. Circulation 94: 28502855.

UECHI M ET AL. 1998. Depressed heart rate variability and arterial baroreflex in conscious transgenic mice with overexpression of cardiac G(s alpha). Circ Res 82: 416-423. 